\section{Dynamic capabilities, operational capabilities (educational-marketing) and performance}

\author{
Adriana Roseli Wünsch Takahashi \\ Federal University of Paraná, Department of Administration, \\ Curitiba, PR, Brazil \\ Sergio Bulgacov \\ Getúlio Vargas Foundation, Administration School, \\ São Paulo, SP, Brazil \\ Mônica Maier Giacomini \\ Federal University of Paraná, Department of Administration, \\ Curitiba, PR, Brazil
}

Received on

11/06/2015

Approved on

$12 / 20 / 2016$

Responsible editor:

Prof. Dr. J. Ignacio Canales

Evaluation process:

Double Blind Review

\begin{abstract}
Purpose - To verify the relationship between dynamic capabilities (DCs) and their impact on performance mediated by operational capabilities, considering educational technological capabilities and marketing capabilities in private higher education institutions (HEIs) in Brazil.
\end{abstract}

Design/methodology/approach - A survey was carried out in 1.932 higher education institutions, resulting in 316 valid insertions. Research involved dynamic capabilities, operational capabilities, performance and environmental dynamism constructs.

Findings - The research revealed the emergence and explanation of a competitor model containing relationships that had not been considered by previous models, i.e., the direct influence of technological educational capabilities on marketing capabilities.

Originality/value - The results revealed greater managerial complexity when referring to the relationship between DCs and performance, and contribute to research concerning HEIs in Brazil and to academic management itself.

Keywords - Dynamic capabilities; operational capabilities; marketing capability; technological capability; performance.

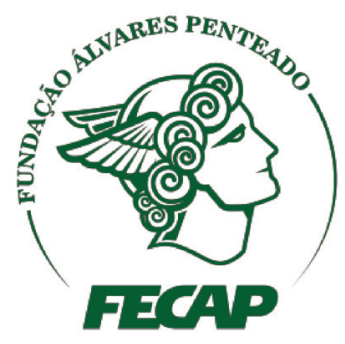

Review of Business Management

DOI: $10.7819 /$ rbgn.v0i0.2831 


\section{Introduction}

Research about organizational performance has long been published by management literature, as well as about its relationship with various categories, such as competencies, strategies and innovation, among others. Currently, in an attempt to understand what we can call 'firm reinvention theory', the concept of dynamic capabilities (DCs), originating from the concept of competencies and the resource based view (RBV), has shown promise in explaining why and how organizations change, adapt and reconfigure themselves through environmental dynamism; in short, they reinvent themselves to survive and maintain competitive advantages.

Although the concept of DCs has already been well explored theoretically, there is still a lack of studies about the organizational processes imbricated in the development and use of these capabilities. One of the gaps is precisely to understand how the relationship between DCs and performance occurs - a relationship that needs empirical studies that investigate the presence of mediators in different environmental contexts, cultural settings and fields of activity. Some studies have already been carried out, such as Wu (2007), Hung, Yang, Lien, McLean and Kuo (2010), Prange and Verdier (2011), Protogerou, Caloghirou and Lioukas (2011), Pavlou and Sawy (2011) Wilden, Gudergan, Nielsen and Lings (2013) and Giacomini (2013). Empirically, the absence of papers that deal with the relationship between capabilities and performance is noticeable. However, these studies have focused on industry sectors, which justifies and makes relevant the choice of a services sector for this research.

The sector chosen was the educational one - specifically private higher education, which is unprecedented research in consulted literature, both nationally and internationally. This sector has undergone many changes over recent years, with changes in operating logic, expansion of the number of institutions and competition in the face of strong competitive intensity. This scenario has increasingly demanded from them the ability to 'reinvent' themselves, be it through acquisitions or innovations, turning it into a relevant locus for studying DCs and performance. The results of this study provide new findings on the relationship between DCs and performance and bring contributions to field studies and to HEIs' academic management.

So, the general objective of this work is to verify how the relationship between dynamic capabilities and performance occurs, through marketing and educational technology operational capabilities applied to the private higher education sector in Brazil.

\section{Theoretical foundations}

In this section, the concepts of dynamic capabilities, marketing and educational operational capabilities, and performance are presented and referring in order to support the hypotheses proposed for this research.

\section{I Dynamic capabilities}

The concept of dynamic capabilities was initially presented by Teece, Pisano, and Shuen (1997, p. 516), and refers to "the firm's ability to integrate, build, and reconfigure external and internal competencies toward environmental change." Since then, other important references have been published. The work of Eisenhardt and Martin (2000) introduces a less economical and more procedural aspect to DCs, giving rise to two different lines of study, as shown by Peteraf, Stefano and Gianmario (2013). One of the discussions that emerged from these two and other subsequent studies concerns the dynamism of the environment, i.e. whether the concept of DCs is relevant only to organizations that are operating in highly dynamic environments (Teece et al., 1997), or are important for organizations operating in a moderately dynamic environment, as argued by Einsenhardt and Martin (2000). Moderately dynamic markets are those in which change occurs with certain frequency, and paths are more or 
less predictable and linear. Within these markets, effective DCs rely heavily on existing knowledge and routines that enable them to take advantage of opportunities (Einsenhardt \& Martin, 2000). However, analyzing how this occurs empirically is a challenge that is still present (Easterby-Smith, Lyles, \& Peteraf, 2009) in various contexts, and further studies are needed, regardless of the line of study adopted.

As an analytical category, the DCs concept has been understood as made up by the following capabilities: to sense (to monitor and identify opportunities), to seize (to assess existing and emerging capabilities, and possible investments) and to reconfigure (to create, extend, and modify the resource base when a company grows and the market changes), according to Teece et al. (1997) and Teece (2007). Other capabilities that have been pointed out as constituting DCs are the capability to learn, to integrate and to coordinate. Thus, according to Zahra, Sapienza and Davidsson (2006), DCs are focused on the strategic changes and the alignment of the organization with the environment, and one of the ways in which this relationship has been studied is precisely through organizational performance. In an effort to understand this relationship, authors such as Spring and Araujo (2014) investigated the mediation of indirect or operational capabilities (Protogerou et al 2011, Wilden et al, 2013), which are described below. It is worth mentioning that operational capabilities are necessary so that dynamic capabilities can exist, since they are responsible for the operationalization of the knowledge.

\subsection{Operational capabilities}

Operational capabilities enable organizations to carry out "an activity on an ongoing basis, using more or less the same technique on the same scale to support existing products and services for the same consumer population" (Helfat $\&$ Winter, 2011, p. 1244). It should be noted that this definition covers both industrial organizations and services, according to the authors, and highlights the possibility of studying them in both contexts. Two operational capabilities have received special attention in the literature of both capabilities and DCs: technological and marketing.

According to Takahashi (2005, p. 258), an "operational capability consists of the skills and information necessary to operationalize, maintain and repair technology, i.e. know-how.” The capabilities referring to technology are those that allow for the development and production of technology, enabling response to rapid changes in the technological environment. To Takahashi (2005, p. 257), technological capability is "conceptualized as accumulated knowledge and the ability to make, understand, use and develop this knowledge to produce new technologies." In this way, as a technological capability, it concerns the field of technology for operationalization.

Marketing capabilities, on the other hand, are those that provide relationships with consumers, allowing for competition when predicting changes in their preferences, as well as for creating and sustaining long-lasting relationships (Song, Droge, Hanvanich, \& Calantone, 2005).

Protogerou et al. (2011) studied the relationship between DCs and performance through marketing and technological capabilities, considering them superior technical capabilities, and validated the model that proposes that dynamic capabilities have an impact on performance, and are also mediated by marketing and technology capabilities. Giacomini (2013) studied the same relationships, but in other sectors and context, and her model revealed that dynamic capabilities have an impact on performance through the relationship between marketing capabilities and technological capabilities. To the authors of both articles, these capabilities are idiosyncratic resources that allow for gaining competitive advantages, and are positively related, although differently in each paper.

In general, DCs can explain how new businesses are created, defined, and discovered, 
based on the quest for opportunities in the environment, by combining strategic resources and market needs through the use of new technologies (Jiao, Alon, Koo, \& Cui, 2013). Therefore, DCs involve both operational, technological and marketing capabilities. This assumption is supported by the proposition that firms with a strong innovation technology base improve the sales force by the influence of their consumers on their product-related expectations (Dutta, Narasimhan, \& Rajiv, 1999). Trainor, Rapp, Beitelspacher and Schillewaert (2010) also verified that technological resources support market orientation.

In short, the relationship between the two operational capabilities - technological and marketing - has been sustained in literature since the work of Dutta et al. (1999), as well as the relationship between them and performance (Song et al., 2005; Trainor, Rapp, Beitelspacher, \& Schillewaert, 2010), among others. More recently, operational capabilities have been incorporated into conceptual models of research on DCs and performance (Protogerou et al., 2011; Giacomini, 2013), a relationship which we explore in more detail in the next session.

\subsection{Performance and dynamic capabilities}

Eisenhardt and Martin (2000) argue that DCs are not guaranteed sources of superior performance, but their development represents a possibility, a potential. Teece (2007) states that there is a need for complementary structures, so that DCs may generate performance improvements (Wilden et al., 2013). Therefore, the relationship between DCs and performance may not be direct or even contextual and situational.

If DCs are a dynamic process and vary over time, then the relationship between process indicators and the organizational results (performance) can be analyzed at a given point in time (transversely) and over time (longitudinally). A static perspective and a dynamic perspective. Given the shortage of studies on the relationship between DCs and organizational performance, studies of both natures are relevant and may bring potential contributions to the field. From a theoretical point of view, this work assumes the assumption that DCs represent an attribute of the organization and are developed over time, and therefore they are variables and represent an organizational process, able to be maintained, potentialized and created, and even atrophied. This is because competences are also developed and atrophied, as Takahashi (2007) has shown. Moreover, DCs involve renewal of competencies.

The first theoretical-empirical studies about DCs and performance were initiated by Wu (2007), highlighting their significance in the performance of start-ups. Hung et al. (2010) demonstrated that organizational learning directly affects performance through the mediation of DCs. Prange and Verdier (2011) validated a model that deals with the relationship between DCs exploratory processes and performance. However, Protogerou et al. (2011) were the ones who studied for the first time, theoretically and empirically, the impact of DCs on performance, mediated by marketing and technological operational capabilities, as this work proposes. THus, this model was selected as reference for this work, along with other contributions such as Pavlou and Sawy (2011), Wilden et al. (2013), and Giacomini (2013).

These articles are mentioned in the next session, which deals with the hypotheses.

\section{Hypotheses}

Based on the consensus in literature that DCs are different from operational capabilities, Protogerou et al. (2011) assume that: (a) capabilities can be both operational and dynamic, and both may reflect a firm's ability to perform a particular activity or function, but (b) operational capabilities help a firm perform basic functional activities, and (c) DCs refer to the transformation and reconfiguration of operational capabilities. The authors analyzed the hypotheses, considering that marketing and technological capabilities are mediators of the relationship between 
DCs and performance. To analyze DCs and performance, the authors considered that renewal and reformulation by DCs according to environmental needs may be a prerequisite to sustainable competitive advantages. The authors used the following subdimensions for DCs: coordination, learning and competitive response.

However, Teece et al. (1997) and Teece (2007) argue that the dimensions of DCs are sense, seize and reconfigure, while Pavlou and Sawy (2011) consider the following capabilities: sensing, learning, integration and coordination. In order to make the DC variable more robust and to investigate it comprehensively, we considered the following dimensions already investigated in literature: sense, seize, reconfiguration, learning, coordination and integration.

Assuming DCs of this magnitude, we considered them to be of higher order or metacapability that allow a firm to exploit lowerorder operational capabilities that are important in identifying and acquiring new marketing and technological capabilities (Protogerou et al, 2011). For the purposes of this study, technological capabilities were considered educational technological capabilities in order to show that they were treated both in the data collection instrument and in the sector-specific analysis, with due language adaptations and previous tests. Thus, $\mathrm{H} 1$ is:

H1: The presence of dynamic capabilities has a positive impact on the development of operational capabilities.

H1a: The presence of dynamic capabilities has a positive impact on the development of marketing capabilities.

H1b: The presence of dynamic capabilities has a positive impact on the development of technological educational capabilities.

Marketing capability empowers firms to better understand customers and their needs, gain new customers and effectively analyze competition and competitors. Technological capabilities enable firms to develop systems and procedures to seek solutions to problems, implement and develop prototypes, and import and absorb external knowledge. Thus, the more a firm is endowed with capabilities that enable it to produce superior or low-cost market supplies, the more these capabilities can be translated into a position of competitive advantage and superior performance. Thus, $\mathrm{H} 2$ is:

H2: Operational capabilities have a positive impact on firm performance.

H2a: Marketing capabilities have a positive impact on firm performance.

H2b: Technological capabilities have a positive impact on firm performance.

To Protogerou et al. (2011), this relationship is not theoretically new, but it is relevant to the completeness of the model, which is reaffirmed in this study. The objective was to consider a positive relationship between operational capability and performance in order to examine the effect of DCs on competitive advantage, through the mediation of operational capabilities. This indirect effect indicated in $\mathrm{H} 1$ and $\mathrm{H} 2$ happens because the superior performance at some point of time is directly influenced by the configuration of operational capabilities $(\mathrm{H} 2)$, which are configured by DCs $(\mathrm{H} 1)$. Thus, $\mathrm{H} 3$ is:

H3: Dynamic capabilities have a positive impact on performance.

Concerning environmental dynamism, we considered that DCs vary according to the degree of this dynamism, a supposition assumed in convergence with Eisenhardt and Martin (2000) and Helfat et al. (2007). Therefore, environmental dynamism was considered in this paper as external and not moderating. In moderately dynamic markets, DCs are found in complicated and 
detailed routines, and in analytical processes to produce mostly predictable results, while in highly dynamic environments they are simple, experiential, and unstable, geared to the rapid creation of knowledge to produce adaptive but unpredictable results. In stable or less dynamic environments, changes are slower and more predictable. Therefore, DCs do not transform operational capabilities, but support their adaptive change through small incremental improvements.

Environmental dynamism and competitive intensity are present in the various theoreticalempirical studies on DCs, and research has considered them both as context and as mediator (Eisenhardt \& Martin, 2000, Helfat et al., 2007,
Protogerou et al., 2011, Teece, 2007, Wilden et al., 2013, Zahra, Sapienza, \& Davidsson, 2006, among others). There is consensus in literature that, in one way or another, it is essential to consider the environment and the sector to which the studied organization belongs. In this way, new studies such as this paper are relevant in order to investigate the relationship between DCs and performance. Thus, $\mathrm{H} 4$ is:

H4: Environmental dynamism has a positive impact on firm performance.

The following figure shows the model that supports the four hypotheses:

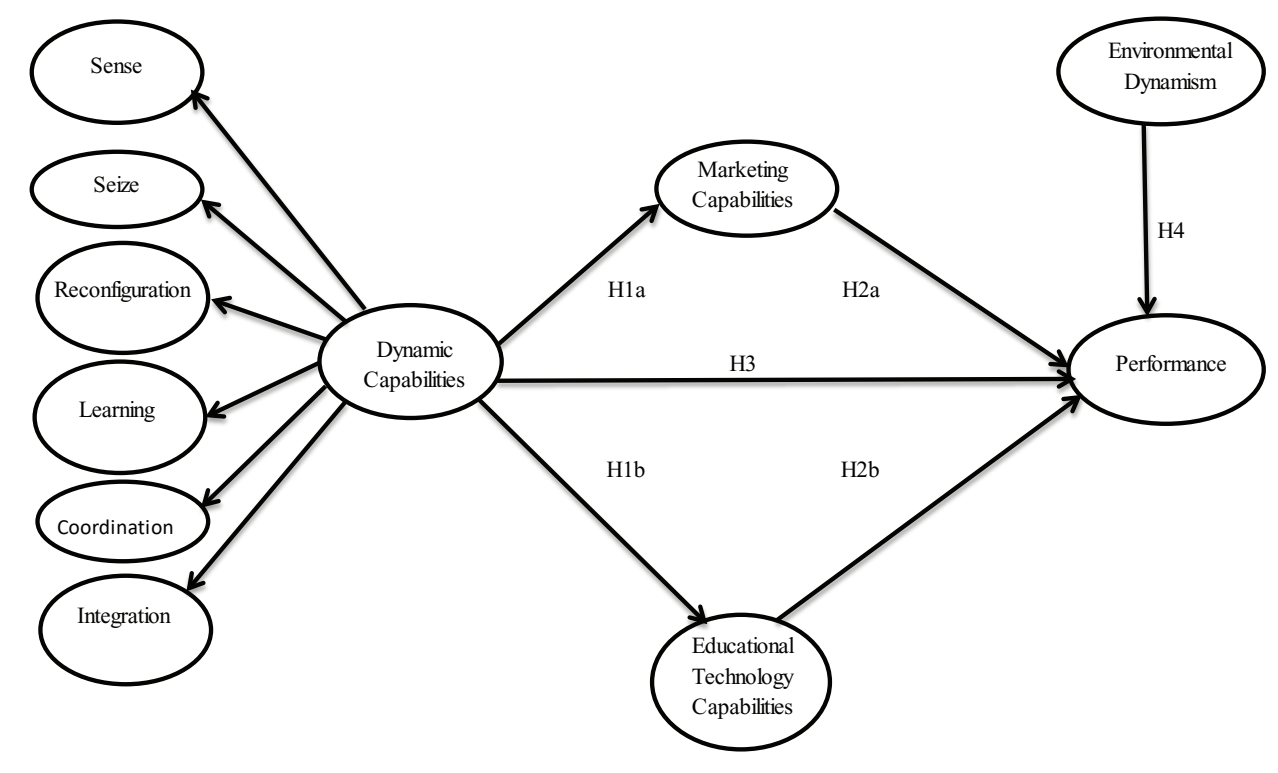

Figure 1. Proposed Model

Source: Adapted from Protogerou, A., Caloghirou, Y., \& Lioukas, S. (2011). Dynamic capabilities and their indirect impact on firm performance. Industrial Corporate Change, 21(3), 615-647. doi: 10.1093/ icc/dtr049

\section{Methodology}

This study's approach is quantitative; it was carried out through a questionnaire survey. The model adopted was that of Protogerou et al. (2011), but with some changes in the composition of DCs based on studies by Teece (2009), Pavlou and Sawy (2011) and Wilden et al. (2013). Unlike the original model by Protogerou et al
(2011), which analyzed the companies in groups of different levels of environmental dynamism, the Environmental Dynamism construct was used as an exogenous variable, since the authors already demonstrated that the impact of DCs on performance occurs in the same way at both levels of environmental dynamism.

The context in which research is applied is national, and the selected sector is the 
educational, specifically private higher education. This sector was chosen because it has undergone significant changes over recent years, both through mergers and acquisitions, as well as in intensified competition and price wars. The offer of educational services has been diversified, showing signs of frequent changes. This segment has specifics because it is a knowledge intensive sector, which can bring new knowledge to the field of DCs both because it belongs to the service sector and because of the type of service it offers. It is noteworthy that no research on DCs and performance in this sector was identified, neither in national nor international literature.

Brazilian private higher education has undergone several changes over the last two decades and has increased significantly (Takahashi, 2007). National Institute of Educational Studies and Research Anísio Teixeira (Instituto Nacional de Estudos e Pesquisas Educacionais Anísio Teixeira/INEP, 2014) data shows the same: in 2013, the total number of students enrolled in Brazilian higher education institutions reached 7.3 million, almost 300 thousand enrollments over 2012; enrollments increased by $3.8 \%, 1.9 \%$ in the public network and $4.5 \%$ in the private network; there are 32 thousand undergraduate courses offered by 2,4 thousand HEIs, of which 301 are public and 2,000 are private; between 2003 and 2013, the number of students enrolled in undergraduate courses increased by $76.4 \%$.

With the growth of the sector, several mergers and acquisitions have occurred due to competitive intensity, either for survival or growth. As an example of the changes that have occurred in the operation of HEIs, both in terms of managerial professionalization and of market logic, we can mention the case of an HEI which, in 2007, for the first time, opened capital in the stock exchange. This context demanded from HEIs new administrative and academic systems and procedures, to act more intensely in the allocation of resources, innovations, strategic renewal and capability development. Both universities and university centers and colleges need a complex enough structure to have their activities regulated, guaranteeing adequacy for the study of capabilities. In addition, the regulation of the operation of HEIs by the Brazilian Ministry of Education has also pressured organizations to professionalize their activities.

\section{I Sample and data collection}

The HEIs sample $\mathrm{n}=316$ (return of $16.36 \%$ ) was based on a cross-sectoral approach to ensure a sufficient sample for the generalization of data from the population of 1,932 private HEIs. Primary data was used for all categories of the research to test the hypotheses, since there are no public reports from HEI allowing for the evaluation of financial performance and of the sale of educational services based on secondary data.

The questionnaire was elaborated based on articles that have already developed and applied scales for studies of DCs and performance (Protogerou et al., 2011, Pavlou \& Sawy, 2011, Wilden et al), as well as on authors such as, for example, Eisenhardt \& Martin, 2000, Helfat et al., 2007; Teece et al., 1997; Teece, 2009. We included questions about DCs and their components, operational capabilities, performance and environmental dynamism. The questionnaire also included questions on respondents' and institutions' profiles. A 5-point Likert scale was used, varying from "totally disagree" to "totally agree", since this is a well accepted practice in this type of research, and appropriate to the application context. The questionnaire was applied through Qualtrics software.

\section{I.I Constructs}

The constructs used in the study are described below, considering the dimensions used in each one of them.

\section{I.I.I Dynamic capabilities}

The DCs construct brought together the dimensions considered by Protogerou et al. (2011), by Pavlou and Sawy (2011) and by Wilden et al. (2013) in order to make it more robust and complete. Such as in the study by Wilden et al. (2013), which was based on Teece (2009), the concept of DCs was considered a second-order multidimensional construct, composed of first order dimensions: capabilities to monitor and identify opportunities (sense), to assess capabilities and possible investments (seize), and to create, extend, and modify the resource base as the business grows and the market 
changes (reconfiguring). These components are not interchangeable and represent different DC processes (Teece, 2009). In addition to these components, we also considered the dimensions of learning, which is understood as the flow of knowledge and experiences, present in the studies of Protogerou et al. (2011) and Pavlou and Sawy (2011); integration which refers to new resources and assets, present in the study of Pavlou and Sawy (2011); and coordination, of organizational and administrative processes, present in the studies of Protogerou et al. (2011) and Pavlou and Sawy (2011). These items were validated in the mentioned research. In summary, we obtained six subdimensions that compose DCs, each with specific items: sense, seize, reconfiguration, learning, coordination and integration. Special attention was given to the learning dimension, since the questions were out of date in relation to literature.

\section{I.I.2 Operational capabilities}

Based on the study by Protogerou et al. (2011) and Giacomini (2013), the items of marketing and technological capabilities were adapted for the educational higher education sector. Marketing capability remained with external emphasis and reflected collective knowledge, skills and resources referring to the needs of the market and consumers, sales force and marketing department. Technological capability focused on educational development, new educational methods, courses and practices, and service processes, with emphasis on the relationship with stakeholders, cooperation with sector associations, with regulatory agencies and educational planners in the country, and with the department academic institution. Therefore, technological capability was hereby named an educational technological capability. In-depth interviews and a pretest allowed us to adjust language and items.

\section{I.I.3 Performance}

Performance was evaluated based on respondents' answers regarding the sale of educational services and financial results, such as in the study of Protogerou et al. (2011) and Giacomini (2013), with the appropriate adaptations to the sector. Educational services included an increase in the number of students, courses and services, investments in sales of educational materials and services, and dropout rates. Financial performance was evaluated in terms of return on investments, market shares, debt ratios, repayment capabilities, and the financial capability to expand with own resources. This performance data was evaluated based on primary data, since there is no national public information database in these categories for HEIs.

\section{I.I.4 Environmental dynamism and competitive intensity}

Based on the scale items of Wilden et al. (2013); Protogerou et al., 2011; Pavlou and Sawy (2011), the questions were created and adapted to the educational sector context. Respondents were asked to assess environmental turbulence, price competition and promotion 'wars', the competitive situation of the higher educational context, competitors' strategies, threats and opportunities in the industry, and marketing practices.

\subsubsection{Adaptation of questionnaire language and pretests}

After the questionnaire was created, we adapted its language to the educational context. To this end, we used the authors of this paper's experience of over 10 years in research, teaching and management in the educational sector. In addition, five in-depth face-to-face interviews were conducted with private HEI managers, each an average one-and-a-half hours long. The respondents provided suggestions on the clarity of the questions and on the structure of the questionnaire; both were then analyzed and inserted into the new version of the research instrument.

Subsequently, the validation of the construct scale was verified through the mean and standard deviation, generated in Qualtrics. Then, a pretest of the questionnaire was conducted with 15 respondents, other than those interviewed in the previous phase; these were all professionals with knowledge and experience in the higher education sector. Respondents gave new suggestions for 
improvements to the questionnaire, which were incorporated, resulting in a third version of the sample data collection - conducted in 2014 instrument. Thus, the language of the questions of the research instrument was considered appropriately adjusted to the Brazilian higher education sector.

All 1,932 HEIs were initially contacted by telephone for the email or telephone of managers. Then managers were contacted and asked to answer the questionnaire. Emphasis on managers as respondents was a way of ensuring that a single response per organization could represent the reality of the HEI in the categories investigated. Several connections were made between July and September 2014, until the sample was large enough to ensure the validity and generalization of the study (316 respondents, one per institution). The positions of the respondents are as follows: dean, vice dean, director, vice director, president and vice president. Regarding the profile of the sample, we found that $38 \%$ of HEIs have been in activity during 11 to 25 years, and 39.9\% during more than 26 years in the market. Regarding the size of HEIs, $77 \%$ are considered medium-sized, according to criterion used by Brazil's Support Service for Micro and Small Companies (Serviço Brasileiro de Apoio às Micro e Pequenas Empresas, SEBRAE), between 100 and 499 employees.

\section{I.3 Validation of measures}

The validity of content was ensured by using scales developed and applied by Protogerou et al., 2011, Pavlou and Sawy (2011), Wilden et al., (2013), and on literature on DCs from the seminal work of Teece (1997). Language adaptation was ensured through the mentioned in-depth interviews, and scale adjustments were performed through a pretest conducted with private HEI managers. These procedures aimed at minimizing measurement errors.

We verified through the use of SPSS that the normal distribution of all indicators presented plausible normality. The standard deviation of the mean demonstrated homogeneity in the evaluation of the respondents, that is, the indexes were below and close to 1 . The construct validity was assured through exploratory factor analysis, which verified the internal consistency of the metrics and extraction of the factors, and by using confirmatory factor analysis (CFA) to ensure the adequacy of the indicators.

The software used in the collection and analysis were SPSS $20^{\text {th }}$ version and AMOS $21^{\text {st }}$ version. Following exploratory factorial analysis and CFA, structural equation modeling (SEM) was performed.

\section{Analysis and discussion of results}

Initially, all dimensions were evaluated by exploratory factor analysis using the principal components method, in which the unidimensionality of the scale was verified. From there on, CFA was carried out, evaluating the relationships between the following constructs: DCs (sense, seize, reconfiguration, learning, coordination and integration), marketing capabilities, educational technological capabilities, performance and environmental dynamism.

\section{I Confirmatory factor analysis}

CFA carried out in this study made use of the Maximum Likelihood estimation method, which is the most commonly used estimation method in the Structural Equation Modeling (Hair, Black, Babin, Anderson, \& Tatham, 2005). We verified in the CFA which model had higher significance; the first option was with the construct of one-dimensional DCs, and the second option was with the construct of $2^{\text {nd }}$ order DCs. We obtained better significance results in the $2^{\text {nd }}$ order model, as shown in Table 1; this is the chosen model to be investigated. The measures of the model presented acceptable adjustment $\left(\mathrm{x}^{2}\right.$ $=856,277, \mathrm{df}=549, \mathrm{x}^{2} / \mathrm{df}=1.56, \mathrm{CFI}=0.94$, $\mathrm{GFI}=0.87, \mathrm{AGFI}=0.843, \mathrm{RMSEA}=0.042)$. All indicators showed $\mathrm{p}>0.000$ significance, which supports the acceptance of the model. Therefore, all indicators presented composite reliability and extracted variance indexes above 0.50 , as suggested by Hair, Black, Babin, Anderson and Tatham (2005), shown in Table 1. 
Adriana Roseli Wünsch Takahashi / Sergio Bulgacov / Mônica Maier Giacomini

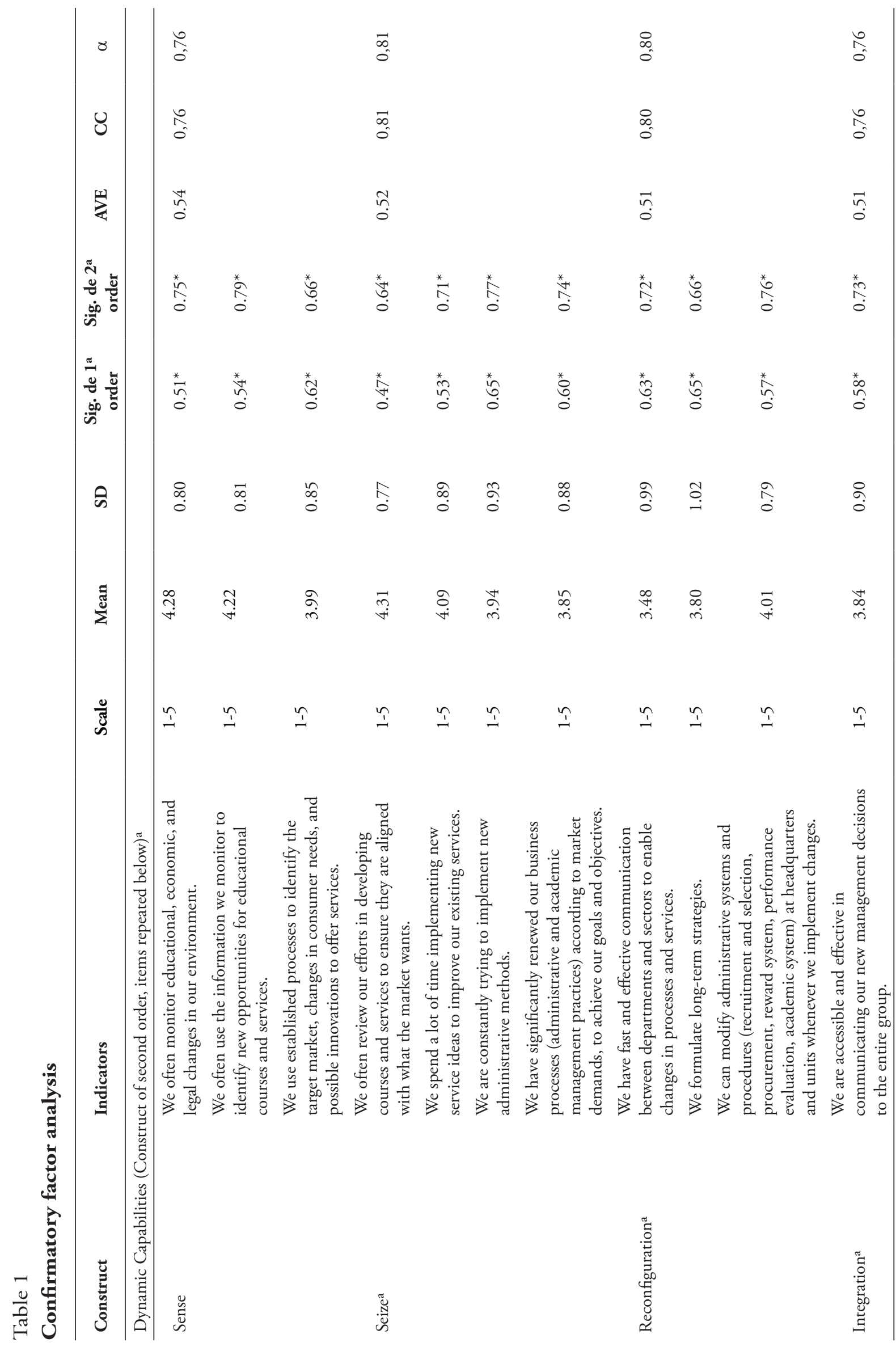




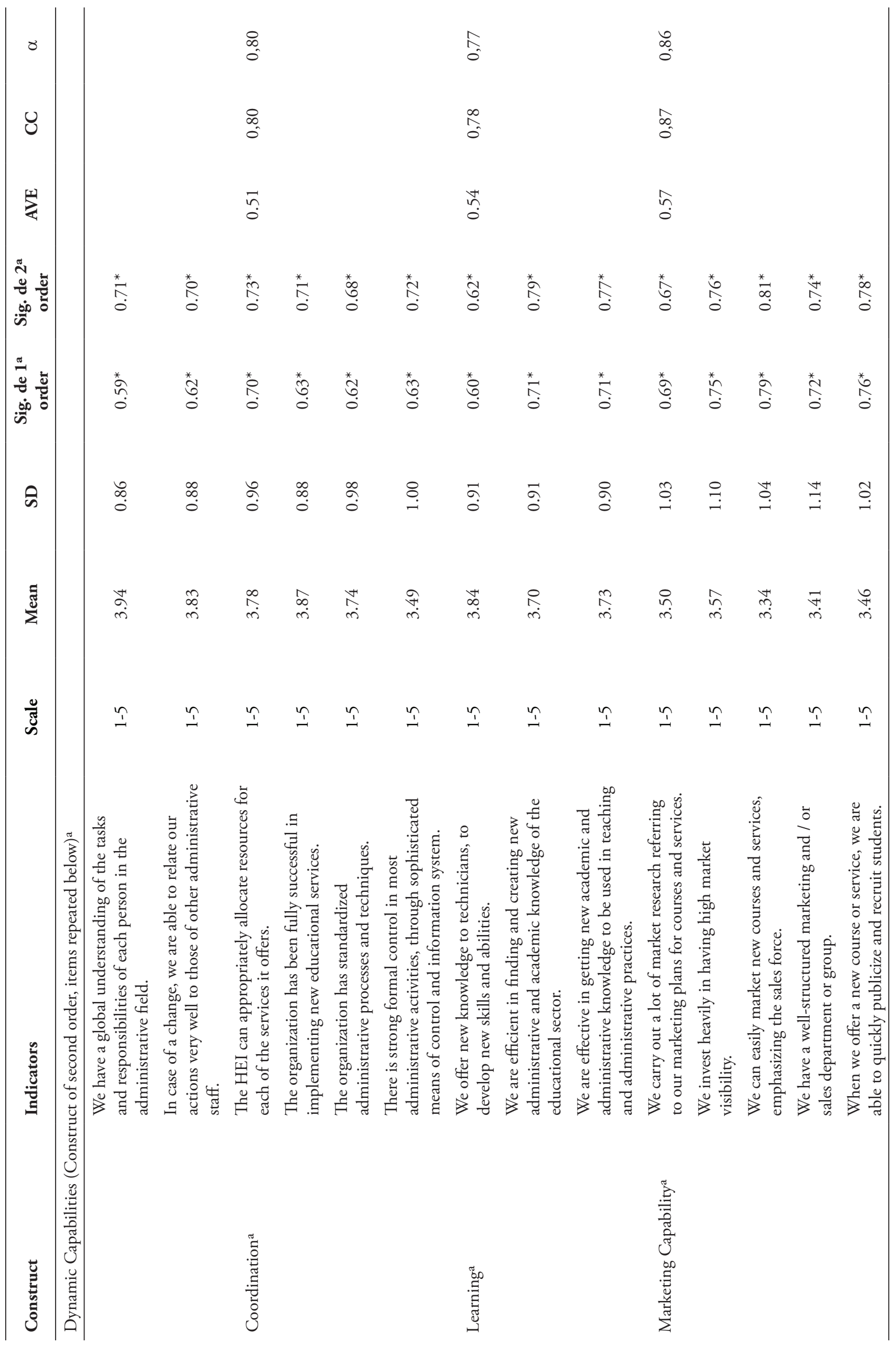


Adriana Roseli Wünsch Takahashi / Sergio Bulgacov / Mônica Maier Giacomini

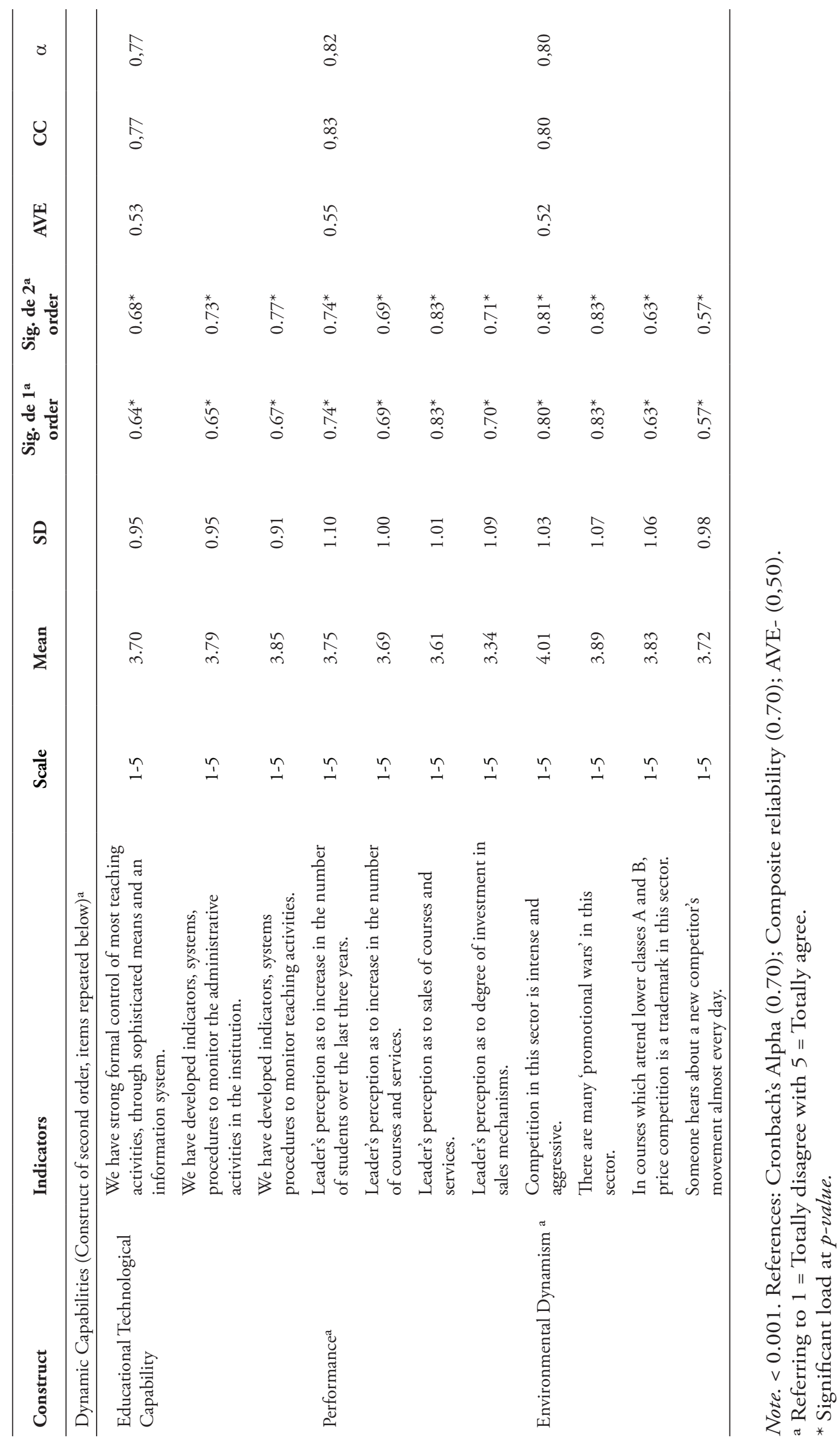


In relation to Cronbach's alpha, all the model's construct indicators presented reliability, considering $\alpha \geq 0.7$ as appropriate reliability (Marôco, 2010). The next step was to evaluate discriminant validity, in which all the AVE constructs were shown to be larger than the squared correlation, with all other constructs, according to Table 2 .

Table 2

\section{Correlation between constructs}

\begin{tabular}{lcccccccccc}
\hline & $\mathbf{( 1 )}$ & $\mathbf{( 2 )}$ & $\mathbf{( 3 )}$ & $\mathbf{( 4 )}$ & $\mathbf{( 5 )}$ & $\mathbf{( 6 )}$ & $\mathbf{( 7 )}$ & $\mathbf{( 8 )}$ & $\mathbf{( 9 )}$ & $\mathbf{( 1 0 )}$ \\
\hline (1) Sense & 1 & 0.53 & 0.32 & 0.27 & 0.39 & 0.34 & 0.22 & 0.14 & 0.11 & 0.03 \\
(2) Seize & $0.73^{* *}$ & 1 & 0.32 & 0.28 & 0.43 & 0.49 & 0.26 & 0.23 & 0.19 & 0.04 \\
(3) Reconfiguration & $0.57^{* *}$ & $0.57^{* *}$ & 1 & 0.50 & 0.48 & 0.48 & 0.47 & 0.43 & 0.30 & 0.01 \\
(4) Integration & $0.52^{* *}$ & $0.53^{* *}$ & $0.71^{* *}$ & 1 & 0.47 & 0.44 & 0.26 & 0.30 & 0.11 & 0.00 \\
$\begin{array}{l}\text { (5) Coordination } \\
\text { (6) Learning }\end{array}$ & $0.62^{* *}$ & $0.66^{* *}$ & $0.69^{* *}$ & $0.69^{* *}$ & 1 & 0.48 & 0.47 & 0.39 & 0.33 & 0.02 \\
$\begin{array}{l}\text { (7) Marketing } \\
\text { Capabilities }\end{array}$ & $0.58^{* *}$ & $0.7^{* *}$ & $0.69^{* *}$ & $0.67^{* *}$ & $0.70^{* *}$ & 1 & 0.39 & 0.43 & 0.17 & 0.05 \\
$\begin{array}{l}\text { (8) Educational } \\
\text { Technological }\end{array}$ & $0.47^{*}$ & $0.51^{* *}$ & $0.69^{* *}$ & $0.51^{* *}$ & $0.69^{* *}$ & $0.62^{* *}$ & 1 & 0.35 & 0.43 & 0.01 \\
$\begin{array}{l}\text { Capabilities } \\
\text { (9) Performance }\end{array}$ & $0.36^{*}$ & $0.47^{*}$ & $0.65^{* *}$ & $0.55^{* *}$ & $0.63^{* *}$ & $0.66^{* *}$ & $0.59^{* *}$ & 1 & 0.17 & 0.01 \\
$\begin{array}{l}\text { (10) Environmental } \\
\text { Dynamism }\end{array}$ & $0.33^{*}$ & $0.40^{*}$ & $0.54^{* *}$ & $0.33^{*}$ & $0.58^{* *}$ & $0.41^{*}$ & $0.65^{* *}$ & $0.40^{*}$ & 1 & 0.00 \\
\hline
\end{tabular}

Note. ${ }^{*}$ Significant at $0.01 ; * *$ Significant at 0.05 .

From these analyzes, it can be verified that the model used in this study is consistent, allowing us to advance to the structural equation modeling (SEM), as shown in the correlation matrix in Table 2 .

\section{$5 \cdot 2$ Structural equation modeling}

Structural equation modeling analysis (Marôco, 2010) indicates that the adjustment measures of the proposed model are within the recommended limits $\left(x^{2}=1114,84, d f=590, x^{2} /\right.$ $\mathrm{df}=1.88, \mathrm{CFI}=0.90, \mathrm{GFI}=0.84, \mathrm{AGFI}=0.81$, RMSEA $=0.053$ ), ensuring the good quality of overall model adjustment by estimated coefficient.

Figure 2 shows the model measured through Amos software, which represents each construct with its significance indicators. The evaluation of the proposed model showed that some indicators had the $\mathrm{p}-$ value $>0.001$. The evaluation of the relationships in the proposed model presented acceptable results, according to recommendations of Hair et al. (2005) on DC relationships and marketing capabilities; DCs and educational technological capabilities, and marketing and performance capabilities. However, the relationship between educational technological capabilities and performance; DCs (sense, seize, reconfiguration, learning, coordination, integration) and performance, environmental dynamism and performance did not present significance in the proposed model, according to initial hypotheses. 


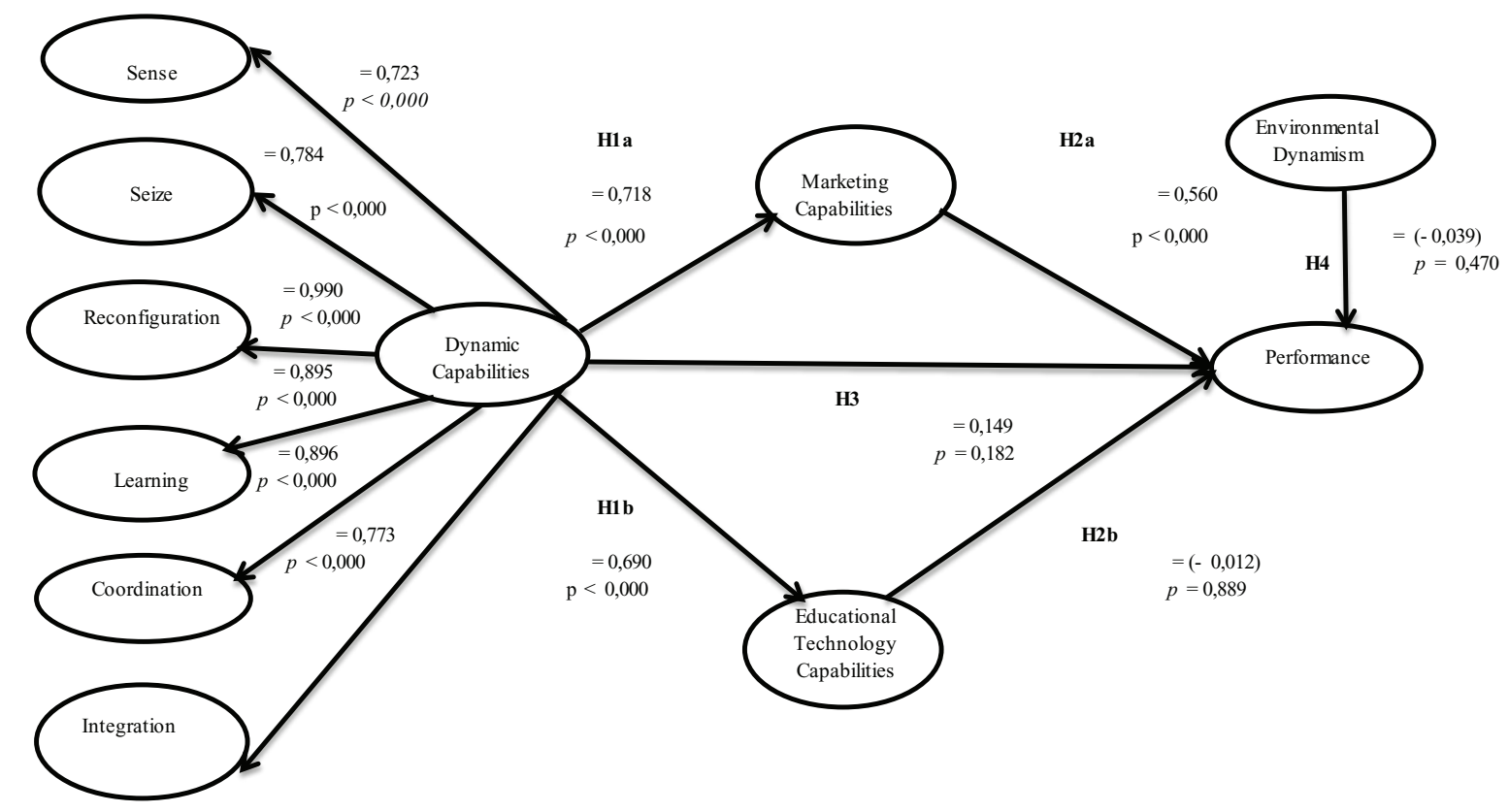

Figure 2. Proposed Model

Source: Research data (2014).

Hypotheses $\mathrm{H} 1 \mathrm{a}$ and $\mathrm{H} 1 \mathrm{~b}$, which deal with the presence of DCs that positively impact the development of marketing and and educational technological operational capabilities were accepted. This shows the explanatory character attributed to DCs, which are considered higher order or meta-capability, allowing a firm to exploit operational capabilities, and identify and acquire new marketing and technological capabilities (Protogerou et al., 2011). This study adds three dimensions of the untreated DCs in the previous model, which in turn had great significance in the relationships, which points to the complexity of DCs, since they are not only composed by the capabilities of sense, seize and reconfiguration and involve other relevant processes: learning, coordination and integration.

The H2a hypothesis, which deals with the impact of marketing capabilities on performance, was accepted, reinforcing this previously supported relationship. This confirms the proposition of Protogerou et al. (2011), which states that the more a firm is endowed with operational capabilities, the more these capabilities can be translated into a performance position. However, hypothesis $\mathrm{H} 2 \mathrm{~b}$, which also deals with an operational capability, of educational technology, was not corroborated in its impact on performance, which brings to the theory an uncertainty in this direct relationship. That is, for the sector analyzed, DCs do not affect the performance through the technological capability, being necessary to investigate how this relationship occurs, which is presented later.

Hypothesis H3 - that DCs have a direct impact on performance - was rejected, which reinforces the role of DCs in transforming and reconfiguring their operational capabilities to achieve superior performance applied to the education sector. This result is not relevant, since, given the complexity of DCs and the existence of different operational capabilities in the organizations, one can expect that the relationship with the performance occurs indirectly.

The last hypothesis, H4, which deals with the environmental dynamism that influences performance, was not accepted in this context, since it did not reveal significance. We emphasize that this is an issue on which there is no consensus 
in literature. What we could verify is restricted to one sector, unlike previous studies that considered several sectors where it is possible to compare results from environments with different levels of dynamism.

Differently from the study by Protogerou et al. (2001) that found positive results in the hypotheses formulated, in this study some hypotheses were rejected. The study by Giacomini (2013) also rejected some hypotheses, but not the same ones as this study. As there is evidence in the literature about the relationships between the operational, technological and marketing capabilities, we tried to develop a Competitor Model that could explain the indirect impact of DCs on performance in the context of private HEIs, as proposed in the work of Giacomini (2013) with industries from different sectors.

\section{$5 \cdot 3$ Competing model}

To create the competing model, we considered that no model is unique in the level of adjustment achieved, and that for any model with acceptable fit there are some alternative models with the same level of fit, as suggested by Hair et al. (2005). The competing model presented the following adjustment measures $\left(\mathrm{x}^{2}=1156,75, \mathrm{df}=590, \mathrm{x}^{2} / \mathrm{df}=1.95, \mathrm{CFI}=0.89\right.$, GFI $=0.83$, AGFI $=0.81$, RMSEA $=0.055$ ) which shows good quality of general adjustment of the model by estimated coefficient, within the recommended limits.

The evaluation of the competing model revealed a path of differentiated explanation, in which the evaluation of the relationships presented acceptable results according to Hair et al. (2005), because all indicators presented significance $\mathrm{p}>0.000$ in the relationships between DCs and educational technological capabilities; educational technological capabilities and marketing capabilities, and marketing capabilities and performance, respectively. Hypothesis $\mathrm{H} 1 \mathrm{~b}$ was accepted, which means that the six dimensions of DCs of the model characterized by the monitoring of the educational sector, identification of new opportunities for educational courses and services, implementation of new ideas regarding the offer of services, formulation of long term strategies, and communication about administrative decisions reflect in the creation and configuration of educational technological capabilities in a positive and meaningful way.

The competing model evidences a new relationship between operational capabilities not previously addressed in the literature, which is the impact of educational technological capabilities on marketing capabilities, as shown in Figure 3. With the theoretical support that states that organizations with a strong base of innovation technology improve the sales force through the influence of their consumers on their productrelated expectations (Dutta et al., 1999), the competing model suggests hypothesis H5:

H5: Educational technological capabilities have a positive impact on marketing capabilities.

Hypothesis $\mathrm{H} 2 \mathrm{a}$ - that states that marketing capabilities have an impact on performance - was accepted, which points to two important results: (a) it confirms the direct and significant connection with firm performance results, (b) it demonstrates that a HEIs' well structured investments in market visibility, sales of new courses and services, sales force, marketing and sales result in the increase of students, courses and services.

The competing model presented a power of explanation $\mathrm{R}^{2}$ in the hypotheses $\mathrm{H} 1 \mathrm{~b}, \mathrm{H} 5$ and $\mathrm{H} 2 \mathrm{a}$ of $61 \%, 51 \%$, and $44 \%$, respectively. In addition, through the analysis of the indirect effects of this study, we can state that the competing model, with the exclusion of certain hypotheses, indirectly explains $88 \%$ of the relationships between DCs and marketing capabilities; 40\% of relationships between DCs and performance; $40 \%$ of the relationships between educational technological capabilities and performance. 


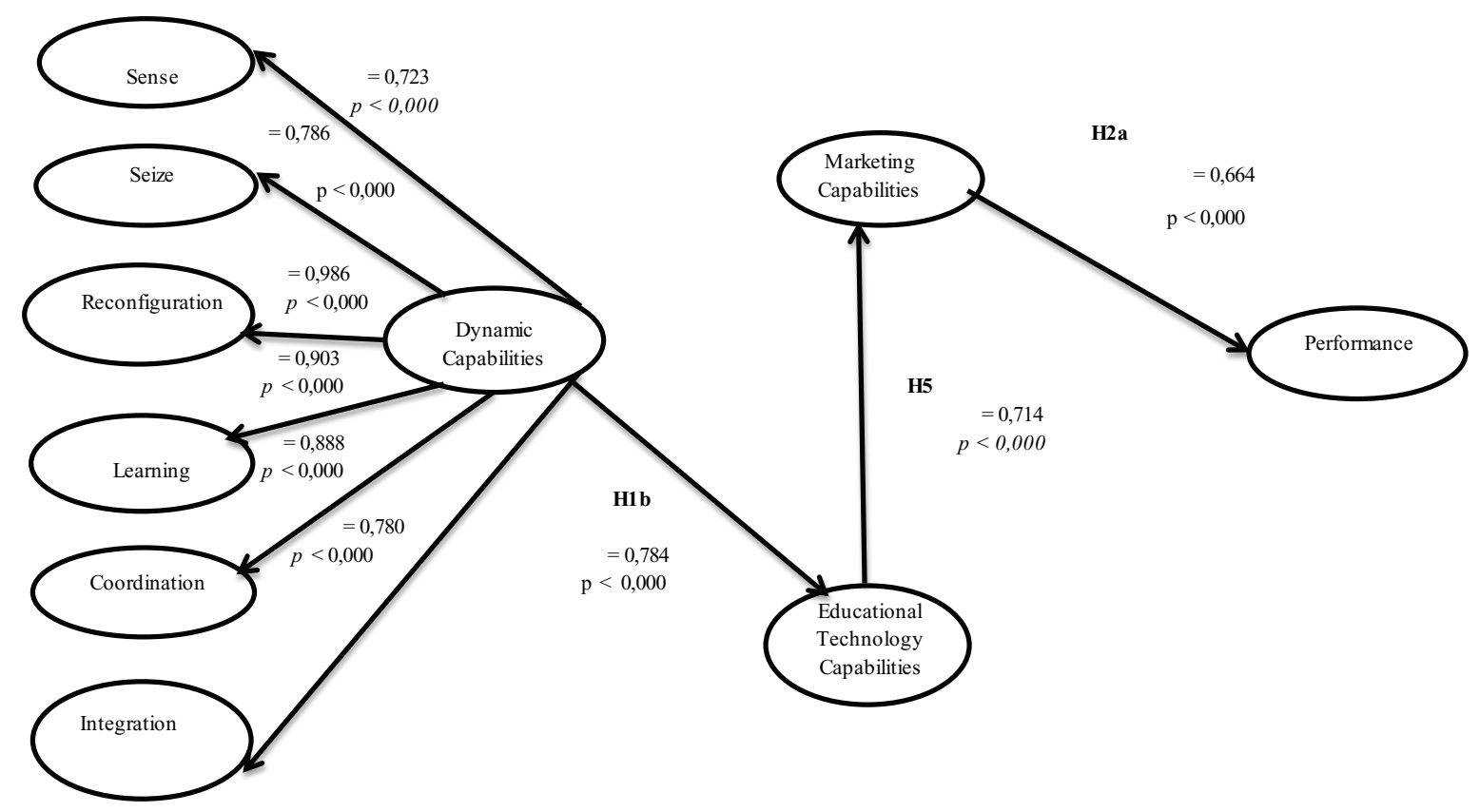

Figure 3. Competing ModelSource: Data base (2014).

\section{Final considerations}

The main objective of the article was the validation of the model adapted from Protogerou et al. (2011) in the Brazilian educational sector, specifically in private higher education, because it is a context that is little explored from the DCs approach, and which presents high price competition and offer of courses.

Three of the six hypotheses in the proposed model were rejected; it explained the impact of DCs on performance through the mediation of marketing capabilities. However, the model did not confirm the direct impact of DCs on performance, and of educational technological capabilities on performance. In addition, there was rejection of the environmental dynamism construct on performance, which demonstrates that competition alone does not directly impact performance, but can be better explained by other factors. From these results, we verified through SEM the existence of a relevant, differentiated explanation path, which was suggested in this study as a competing model.

The competing model suggests that DCs impact performance through the mediation of operational capabilities, marketing capabilities and educational technological capabilities, for a different course in the case of private HEIs. A new relationship not treated in previous models was found in this study, which was the direct impact of educational technological capabilities on marketing capabilities. The theoretical assumptions identified in literature allowed for the creation of hypothesis $\mathrm{H} 5$, which confirmed this relationship in a positive and significant way.

But what do these results express most explicitly as to the educational sector in the segment of private higher education? The context considered in this study revealed that: (a) Brazilian HEIs have in fact sought to identify changes in the market, identify opportunities for educational courses and services, align services in relation to what the market wants, renew these processes and implement the changes (Dimensions of DCs); (B) educational technological capabilities are guided and reconfigured by DCs through information systems that in turn allow formal control and monitoring of teachers' activities, and through the use of indicators; (C) the positive impact of DCs on educational technological capabilities reflects in the marketing capabilities that, through 
the development of market research and the marketing of courses and services, are able to place more emphasis on the sales force of private HEIs. This course reflects HEI efforts to achieve superior sales performance and service offerings.

Educational technological capabilities issues that have remained after the adjustment reflect that these refer to the formal control of teaching activities, and the development of indicators, systems and procedures to monitor administrative and teaching activities. That is, the effect of DCs on educational technological capabilities relates to a positive effect centered on these dimensions of technological operational capability, not on issues specifically linked to innovation. What do DCs refer to in this segment of activity in the private context? The six dimensions validity for DCs point out that the DCs of the HEIs are composed, in addition to the capabilities of sense/seizing, for coordination, learning, integration and reconfiguration capabilities.

From the point of view of DCs, the results seem to show significant efforts by HEIs to monitor the environment, seize opportunities, reconfigure their resources, integrate and coordinate activities, and efficiently use new administrative and academic knowledge. However, these efforts are having a positive impact on educational technological capabilities focused on controlling and monitoring activities predominantly to which marketing capabilities can positively impact performance.

In sum, this study brings some relevant contributions, such as: (a) the validation of a more complete DCs construct and for the educational services sector, which could be used in future researches, (b) the evidence of how the mediation of DCs and performance in private HEIs in Brazil; (C) the development of a new operational capabilities hypothesis. As for the practical aspects of private HEIs, some results deserve to be highlighted, since they can help in the management of organizations: the configuration of the sector's educational technological capabilities, the configuration of DCs that reveals the bases of innovation in the sector, and elucidation of the bases on which superior performance has been sought after.

Finally, it is worth mentioning an analysis, or at least a doubt, concerning the bases on which the performance and competitive advantage among private sector HEIs have occurred. Given the scenario of accelerated increase in the supply of higher education in the national scenario of recent years, and that the relationship of the search for performance has been given by the evidence, what would be the tendency of a 'dispute' among HEIs whose educational technological capabilities are based predominantly in the control and monitoring of educational activities? It is not a matter of questioning the pertinence of this control, necessary in several organizations. Facing the recent mergers and acquisitions that are occurring and which may change the industry landscape, however, would there be scope for technological changes geared to other dimensions beyond these? New studies are needed to analyze educational technological capabilities and to understand in more depth.

We considered that future research can cover other service-related sectors, even in the public and private educational sector, to verify the consistency of these results in the models tested. The main limitation found in the research was the difficulty of respondents to fill in all its fields, because there was an approximate $14 \%$ loss of questionnaires. This may have been caused by the great number of questions requiring some reflection, or even by lack of time.

\section{References}

Dutta, S., Narasimhan, O., \& Rajiv, S. (1999). Success in high-technology markets: is marketing capability critical? Marketing Science, 18(4), 547-568. doi:10.1287/ mksc.18.4.547

Easterby-Smith, M., Lyles, M. A., \& Peteraf, M. A. (2009). Dynamic capabilities: current debates and future directions. British Journal of Management, 2O(s1), 1-8. doi: 10.1111/j.1467-8551.2008.00609.x 
Eisenhardt, K. M., \& Martin, J. A. (2000). Dynamic capabilities: what are they? Strategic Management Journal, 21(10/11), 1105-1121. doi: 10.1002/1097-0266(200010/11)21: 10/11<1105::AID-SMJ133>3.0.CO;2-E

Giacomini, M. M. (2013). Capacidades dinâmicas e suas influências no desempenho de firma (Dissertação de mestrado). Pontifícia Universidade Católica do Paraná, Curitiba, PR, Brasil.

Hair, J. F., Jr., Black, W. C., Babin, B. J., Anderson, R. E. \& Tatham, R. L. (2005). Análise multivariada de dados. 5. ed. Porto Alegre: Bookman, 2005. 593 p.

Helfat, C. E., Finkelstein, S., Mitchell, W., Peteraf. M. A., Singh, H., Teece, D. J., \& Winter, S. G. (2007). Dynamic capabilities: understanding strategic change in organization. Malden, MA: Blackwell Publishing.

Helfat, C. E., \& Winter, S. G. (2011). Untangling dynamic and operational capabilities: strategy for the ever-changing world. Strategic Management Journal, 32(11), 1243-1250. doi: $10.1002 /$ smj.955

Hung, R. Y. Y., Yang, B., Lien, B. Y-H., McLean, G. N., \& Kuo, Y-M. (2010). Dynamic capability: impact of process alignment and organizational learning culture on performance. Journal of World Business, 45(3), 285-294. doi: 10.1016/j.jwb.2009.09.003

Jiao, H., Alon, I., Koo, C. K., \& Cui, Y. (2013). When should organizational change be implemented? The moderating effect of environment dynamism between dynamic capabilities and new venture performance. Journal of Engineering and Technology Management, 30(2), 188-205. doi: 10.1016/j. jengtecman.2013.01.005

Marôco, J. (2010). Análise de equaçôes estruturais: fundamentos teóricos, Software \& Aplicaçóes. Pêro Pinheiro: Report Number.

Pavlou, P. A., \& Sawy, O. A. (2011). Understanding the elusive black box of dynamic capabilities.
Decision Sciences Journal, 42(1), 239-273. doi: $10.1111 / \mathrm{j} .1540-5915.2010 .00287 . \mathrm{x}$

Peteraf, M., Stefano, G. D., \& Gianmario, V. (2013). The elephant in the room of dynamic capabilities: bringing two diverging conversations together. Strategic Management Journal, 34(12), 1389-1410. doi: 10.1002/ smj.2078

Prange, C., \& Verdier, S. (2011). Dynamic capabilities, internationalization processes and performance. Journal of World Business, 46(1), 126-133. doi: 10.1016/j. jwb.2010.05.024

Protogerou, A., Caloghirou, Y., \& Lioukas, S. (2011). Dynamic capabilities and their indirect impact on firm performance. Industrial Corporate Change, 21(3), 615-647. doi: $10.1093 / \mathrm{icc} / \mathrm{dtr} 049$

Portal INEP: site: http://portal.inep.gov.br/ visualizar/-/asset_publisher/6AhJ/content/ matriculas-no-ensino-superior-crescem-3$<$ acesso em 20.09.2015>.

Song, M., Droge, C., Hanvanich, S., \& Calantone, R. (2005). Marketing and technology resource complementarity: an analysis of their interaction effect in two environmental contexts. Strategic Management Journal, 26(3), 259-276. doi: 10.1002/smj.450

Spring, M., \& e Araujo, L. (2014). Indirect capabilities and complex performance. International Journal of Operations \& Production Management, 34(2), 150-173. doi: 10.1108/IJOPM-01

Takahashi, V. P. (2005). Transferência de conhecimento tecnológico: estudo de múltiplos casos na indústria farmacêutica. Gestão e Produção, 12(2), 255-269. doi: 10.1590/S0104-530X2005000200009

Takahashi, A. R. W. (2007). Descortinando os processos da aprendizagem organizacional no desenvolvimento de competências em instituiçôes de ensino (Tese de Doutorado, Universidade de São Paulo - USP, 2007). 
Teece, D. J. (2007). Explicating dynamic capabilities: the nature and microfoundations of enterprise performance. Strategic Management Journal, 28(13), 1319-1350. doi: $10.1002 /$ smj.640

Teece, D. J. (2009). Dynamic capabilities and strategic management. Oxford: Oxford University Press.

Teece, D. J., Pisano, G., \& Shuen, A. (1997). Dynamic capabilities and strategic management. Strategic Management Journal, 18(7), 509-533. doi: 10.1002/ (SICI) 1097-0266(199708) 18:7<509::AIDSMJ882>3.0.CO;2-Z

Trainor, K. J., Rapp, A., Beitelspacher, L. S., \& Schillewaert, N. (2011). Integrating information technology and marketing: an examination of the drivers and outcomes of e-marketing capability. Industrial Marketing
Management, 4O(1), 1-13. doi: 10.1016/j. indmarman.2010.05.001.

Wilden, R., Gudergan, S. P., Nielsen, B. B., \& Lings, I. (2013). Dynamic capabilities and performance: strategy, structure and environment. Long Range Planning, 46(1/2), 72-96. doi: 10.1016/j.lrp.2012.12.001

Wu, L-Y. (2007). Entrepreneurial resources, dynamic capabilities and start-up performance of Taiwan's high-tech firms. Journal of Business Research, 60(5), 549-555. doi: 10.1016/j.jbusres.2007.01.007

Zahra, S. A., Sapienza, H. J., \& Davidsson, P. (2006). Entrepreneurship and dynamic capabilities: a review, model and research agenda. Journal of Management Studies, 43(4), 917-955. doi: 10.1111/j.14676486.2006.00616.x

\section{Supporting agencies:}

Brazil's National Council for Scientific and Technological Development (Conselho Nacional de Desenvolvimento Científico e Tecnológico, CNPq)

\section{About the authors:}

1. Adriana Roseli Wünsch Takahashi, PhD in Management, Federal University of Paraná, Brazil.

E-mail: adrianarwt@terra.com.br

2. Sergio Bulgacov, PhD in Management, Getúlio Vargas Foundation, São Paulo Business Administration School, Brazil. E-mail: s.bulgacov@gmail.com

3. Mônica Maier Giacomini, MSc in Management, Pontifical Catholic University of Paraná, Brazil.

E-mail: monimaier18@gmail.com

\section{Contribution of each author:}

\begin{tabular}{lccc}
\hline Contribution & $\begin{array}{c}\text { Adriana Roseli Wünsch } \\
\text { Takahashi }\end{array}$ & $\begin{array}{c}\text { Sergio Bulgacov } \\
\text { Mônica Maier } \\
\text { Giacomini }\end{array}$ & $\sqrt{ }$ \\
\hline 1. Definition of research problem & $\sqrt{ }$ & $\sqrt{ }$ \\
$\begin{array}{l}\text { 2. Development of hypotheses or research questions } \\
\text { (empirical studies) }\end{array}$ & $\sqrt{ }$ & $\sqrt{ }$ & $\sqrt{ }$ \\
3. Development of theoretical propositions (theoretical Work) & $\sqrt{ }$ & $\sqrt{ }$ \\
4. Theoretical foundation/ Literature review & $\sqrt{ }$ & $\sqrt{ }$ \\
5. Definition of methodological procedures & $\sqrt{ }$ & $\sqrt{ }$ \\
6. Data collection & $\sqrt{ }$ & $\sqrt{ }$ \\
7. Statistical analysis & $\sqrt{ }$ & $\sqrt{ }$ \\
8. Analysis and interpretation of data & $\sqrt{ }$ \\
9. Critical revision of the manuscript & $\sqrt{ }$ & $\sqrt{ }$ \\
10. Manuscript Writing & $\sqrt{ }$ & $\sqrt{ }$ & $\sqrt{ }$
\end{tabular}

